\title{
The Problem And Countermeasures Of Application-Oriented College's MOOC
}

\author{
Yi-hong $\mathrm{XU}^{1,{ }^{*}}$ and Hong-zhen DENG ${ }^{2}$ \\ 1, * Jianghan University, Wuhan, 430056, China \\ ${ }^{2}$ Jianghan University, Wuhan, 430056, China
}

Keywords: Application-oriented college, MOOC, Countermeasures.

\begin{abstract}
The application-oriented college refers to the undergraduate institutions, whose train targets are to train the application-ability persons. MOOC has many notable advantages that regular higher education doesn't have. MOOC has challenged the traditional mode of higher education revolutionarily. The thesis mainly used literature methodology and standard methodology, analyzed the problems that application-oriented college's MOOC faced, and put forward countermeasures and suggestions. The thesis drew a conclusion that application-oriented College's MOOC can help the whole society, especially the higher education researchers to rebuild the relationships between "teaching" and "learning", to reconstruct the educational value and to reconstruct the teaching management model in three aspects, such as social attributes, scientific attributes, and manage attributes.
\end{abstract}

\section{Introduction}

\section{Value and Significance of the Selected Topic}

With the development of internet technology and magnification of social competition, people's desire for knowledge reaches a new step. In this kind of situation, MOOC are born at the right moment. MOOC (Massive Open Online Courses) are free courses which are offered by world's top universities. We can sign up and watch the courses only with a mailbox. Coursera, EDX and udacity are called "three carriages". World's top universities initiate MOCC's main force Stanford University, Oxford University, Harford University, MIT and Yale University to open MOOC. In 2013, several domestic famous universities such as Peking University, Tsinghua University did relative experiments and practices and opened lots of MOOC in china. MOOC have many notable advantages that regular higher education doesn't have. MOOC challenge the traditional mode of higher education revolutionarily. It will have profound influences in higher education's future.

Application-oriented college refers to undergraduate universities whose running principle of college is application. Application-oriented college takes outlook on talents, outlooks on quality and outlook on education which reflect the spirit of the time and requirement of social development as leader. It build new discipline orientation, specialty structure and curriculum system which satisfy the needs of economical and social development; it renew teaching contents ,teaching progress, teaching method and teaching means; it improves teaching level roundly and rear high quality practical talents with social adaptation ability and competition. However application-oriented college grew out of academic education. Because of its traditional of thinking and education system, application-oriented college is an elite education mode fundamentally. It has widespread phenomenon: teacher centered, textbook centered, 
and classroom centered. In learning pattern, it is "reception learning": teachers impart learning materials served as ready-made conclusive knowledge; they don't repeat the process that people discover and form the relative knowledge. Application-oriented college ignores students' inactive, motility and independence. It also go against students' potential abilities and innovation quality. What's more, compared to academic research universities, application- oriented college's brand benefit, scientific research strength, historical culture accumulation and many other aspects are much lower than them.

Discussing application-oriented college's developing MOOC can help the whole society, especially the higher education researchers realize the revolutionary impact that MOCC may bring to the future higher education, rebuild the relationships between "teach" and "learn", reconstitute educational value and reconstruct teaching management model in social attributes, scientific attributes, and manage attributes these three aspects. Discussing this contribute to national higher education's management department and universities. They are more likely to free our mind, renew our ideas, and bring MOOC into campus' developing strategies in the height of servicing society and take on educational responsibilities; in the angle of founding the influence and vitality of word first class universities; in the aspect of seizing world's "bridge tower" of knowledge resource and knowledge economy. Discussing application-oriented college's developing MOOC can improve application-oriented college's competitiveness realize interaction between organization and environment, avoid "the situation of the stronger the stronger, the weaker the weaker" and even the risk of being weeded out and dying out.

\section{Commentary Domestic and Overseas Similar Research}

The research team use "MOOC" and "Massive Open Online Course" as index word to retrieve English academic literatures in EBSCO. We get English literature 934 from index word "MOOC" and get English literature 889 from index word "Massive Open Online Course". In addition to that, we get English literature 11354 from "e-learning". To analyse the result of EBSCO, all in all, there are not many literatures relative to MOOC. From the aspect of time when academic articles were published, high quality academic articles showed up in 2012, 2013 and 2014, people who pay attention to MOOC are from colleges and universities .From research topic, most articles exist in curriculum design, explosion and technology relative to MOOC according to relevancy in EBSCO. There also are comparative researches which are based on different technical form. Although they pay little attention to learners, interactive learning and assessment, they have though over these aspects.

As for Chinese literature, we also use "MOOC" as index word to retrieve to retrieve relative articles in CNKI. We get 105 Chinese academic theses highly relative to MOOC and published during 2012 to 2015 May. Just from volume, there are far more fewer Chinese academic literatures than English academic literatures. This result corresponds to the situation of MOOC's development at home and board.

For further analyzing, the research team find that there are few researches about MOOC at home and aboard, and relative researches have small depth and breadth, they lack massive and comprehensive research. Our country's researches are still exploring phase. Most of the researches are aimed at MOOC's notions, features, advantages, influences to domestic traditional education, platform and technology, commercial operating pattern and market potential. However, these researches rarely touch on MOOC's construction. Here are influential researches: 
The Meanings, Features and Types of MOOC. It is stated that the term "MOOC" was named by Bryan Alexander and Dave Cormier, later this term was used by George Siemense and Stephen Downes when they opened a massive open online course "connectivism: A Learning Theory for the Digital Age"(Wangwenli 2013).On 2012 16th September Wikipedia gave the notion "MOOCs are the courses that participants are from all over the world .Many MOOCs provide interactive users forums to support community interaction between students, professors and teaching assistant."

On 2012 20th September, the definition turned to "MOOCs are online course aimed at unlimited participation and open access via the web. MOOCs often emphasized open -access features, such as open licensing of content, structure and learning goals to promote the reuse and remixing of resources. "(HeBin 2014)

The Differences between Small Classed, Open Course Ware and MOOC. LiZhengyu and HuanMeiyan (2014) think that MOOC have more advantages in interaction, teaching aim, certification authentication and learning of evaluation compared to small classed and Open CourseWare. In the meantime MOOC have great influence in traditional higher education.

The Local Researches of MOOC. WangWenli(2013) has discussed that MOOC's developments have great influence on higher education, he also thought chances exist with challenges. The developments of MOOC can't ignore MOOC's localization. GuXiaoqing (2013) has discussed the possibility of MOOC's localization and different challenges that MOOC may face.

\section{The Problems That Application-oriented College's MOOC meet}

MOOC of application-oriented college have met following challenges.

\section{Relative Institution Isn't Perfect}

MOOC are still fresh things to higher education. Although the nation's educational department and local educational departments at all levels have introduced relative files to encourage the development of education informationization and relative plans to encourage MOOC's development, supporting system of all aspects haven't been perfected. That mainly shows in following aspects:

Incentive mechanism isn't perfect. In the short term, MOOC's main pusher is every colleges and universities and every research institution. MOOC's joint development must base on builders' mutual benefit. The educational resources between every colleges and universities aren't balance. And the pale of development between them are different. So every colleges and universities who have high quality resources will input more resources, while regular institutions of higher learning have less resources and less experience in information-based teaching. Benefit distribution isn't fare, so the motivations of colleges and universities are scare. What's more, some teachers may be replaced even weeded out by MOOC, so these teachers who share the same courses with MOOC may prevent MOOC.

Systems of Intellectual Property Protection Is Absent. Compared with foreign massive online courses, the resource construction of domestic MOOC has much difficulty in fain the support of developers and scholars. The main reason is that online resources are lacking of intellectual property protection. In western countries institution of higher learning has established Legal Service Administrator to manage online courses' intellectual property declaration, project and maintenance. Although our people have been aware of intellectual property protection, they only notice commercial 
field, they put little attention to educational field especially the protection of digital intellectual property. MOOC's high quality resources must be supported by teachers' vast creative academic achievement. When crucial contents or core technology being plagiarized and embezzled, or intellectual property rights' definition isn't clear, disputes will be caused and teachers' academic achievements won't get valid protection. The teacher will hardly show any enthusiasm to establish MOOC.

Evaluation Systems haven't been Established. Education needs an evaluation criterion to decide its success or failure, no exception for MOOC. According to our research and analysis of MOOC at home and aboard, our research team thinks that MOOC's evaluation systems contain evaluation of MOOC's quality system and evaluation of performance. Although our country has begun to exploring MOOC, we haven't established a thorough quality evaluation system. For example, what kind of MOOC is qualified; how to assess the level of these courses; how to standard the license issuing system, these all need institutionalization and standardization. Meanwhile, although some domestic MOOC have inserted online questionnaires for their courses, they lack, even don't have scientific yard stick for learning performance.

\section{MOOC's Constructions Are Low}

Foreign MOOC have developed quickly just in short times, they are based on many years' mature high quality resources and technologies. As for domestic MOOC's construction, they lack long- term mechanism and pursuit "volume" rather than "quality", hence our MOOC's constructions have weak economic foundation and little motive power. Although, in recent years our higher education has practiced informationized education such as "excellent course", "micro class competition", we still exist many problems. The author thinks that our MOOC's constructions have following three problems.

High Quality Courses' Resources Are Scant, and the Development of High Quality Courses Is Slow. Making a general survey of foreign mature MOOC, their development is based on massive high quality courses. For example, Coursera grows up after being supported strongly by Stanford University's online courses, EDX also based on online courses' platform which is established by MIT's OCW (open course war). As for our excellent courses construction, we rarely use excellent courses and video-courses account for a little portion. Many colleges and universities as well as teachers only apply for excellent courses, they haven't made long-term plan for the construction of courses. What's more, many resources are only ordinary teaching materials like web lesson plans, they updates data slowly and they are less targeted. Meanwhile, domestic online courses is lacking of compatibility, and they haven't form valid and sustainable research mechanism. That can't help re-develop MOOC according to the teaching situation, that cause many low quality courses and lots of famous courses but without facts.

There Are Barriers between Every Colleges and Universities, and, That Will Obstruct the Share of High Quality Resources between Them. America's MOOC developed with the help of several top universities and colleges, however our MOOC are in the phase of self-sufficiency. From the aspect of resources' management, many domestic colleges and universities setting a high threshold to others, they process exclusive resources so others can't share the high quality resources with them. The operation between every colleges and universities can only happen in a small circle. From the aspect of technology, our country hasn't set up a unified standard system of MOOC, and many every colleges and universities use their own platform to construct 
MOOC. And that makes it difficult to exchange data between every colleges and universities.

MOOC Are Simple They Can't Meet the Needs of Learners Who Use MOOC. Compared to traditional online cources, MOOC have large scale: beneficiaries become larger, learners have more opportunities to participate. Learners can break through their learning phases. MOCC have many learners, some are students who want to prepare lessons before class and review their specialized courses, some learners want to get diplomats of elite schools, others want to study some courses that they have missed after working. Different learners have different learning contents, learning goals and learning progress. MOCC's learner are multiple, however domestic academic world hasn't studied MOOC's classificatonmanafement. Single courses can't cover multiple learning needs, thus domestic MOOC may in dilemma and the extensive educational resources may be reused.

\section{Supporting Service Isn't Perfect}

Another important choke point that MOOC meet is relative supporting service. Our country misunderstand that only education sector and educational experts are responsible for the development of educational informationizaton. The ten-year development plan says we should improve resources' mechanism including government guidance, multi-participation and joint construction and sharing. However, local government education sector and institution of higher learning only deploy macroscopically, they haven't got a perfect service institution or service system to support MOOC's localization.

Domestic MOOC lack market promotion. Compared to foreign MOOC's mode of operation, on the one hand, domestic MOOC start late, have little experience in market promotion, and domestic MOOC's mode of operation concentrates on colleges and universities' administrative means from top to bottom. Because some colleges and universities haven't improved the benefit distribution system of MOOC, they are afraid of market promotion. On the other hand, although MOOC have definite market space, MOOC have to input a lot of money in early days, its payback period is long and its income is relatively low. What's more, MOOC can be greatly influenced by education sector's policy. So investment corporation and social institutions have no desire in participating MOOC's conatitution.

MOOC Techonology's Supportive Force is Weaken. The development of MOOC is closely linked to stable hardware equipment and friendly client supporting system. Compared with overseas MOOC technology environment, our domestic wireless network's transmission speed is slow, stability is weak. Websites for courses are inappropriate and its interaction is low. Without the professional team to do the market survey and data collection that the online function cannot satisfy the needs of the users. It only can be regarded as mathematics' learning materials or reference documents.

Colleges and Universities Lack of MOOC Business Training Service. Not only to the universities, but also to the learners that MOOC is a totally new teaching pattern and method. Recording to that many teachers have rich teaching experience but not do as well as using the informational method. So it may lead to the elimination in this kind of course selection. For diversified learner, since everyone's knowledge background and the ability to master the technology are different. So only under the support of the relevant training service can the teachers skilled use the MOOC to do the study activities. However, many colleges and universities do not attach much importance to 
the teacher's pre-job training and the users' informational operation training. So that many teachers and students just regard this kind of teaching pattern as an ideal one.

\section{Ways of MOOC Construction in Application-oriented College}

\section{Perfect Relevant System to Insure MOOC Can Get the Long-term Development.}

Arouse the Enthusiasm of All the Participators. MOOC construction itself does need the creative cooperation of the constructor. But universities' manager may believe that the advantage of online courses' exploiting for the development of university cannot be shown within the short-term run. In the other hand teachers are lack of enthusiasm to the exploitation and application of the course for they are in the dilemma of focusing more on the scientific research rather than teaching. So education authorities should take informational education development level into the standards of evaluating the universities' educating ability, teacher's professional title and scientific researching ability, establish a long-term evaluating system.

Establish the curriculum standards evaluating system. Curriculum standards and system of rewards and penalties for construction quality. At the point of the system constructing, we need to drew lessons from the past. On the one hand, we should combine the foreign evaluating standards. On the other hand, we ought to refine the standards, set up a learner-oriented system, for example, divide the online course into many parts. And every part needs to be refined again to make the course evaluation to reach the legal basis level.

\section{Actively Guide the Commercialized Operation Mode, Explore the Ways of All Participators' Co-construction and Sharing}

Higher education's commercialized operation mode is not only mean the profit, it also include that encourage social groups to take pat in co-construction and sharing of the resource in direct or indirect ways to make full use of the basic function of market system in resource dividing. MOCC developed in university but the commercialized operation mode's tuition source and core evaluation will be away from the conception of operation which belongs to the university. Two basic rules in bringing in commercialized mode which should pay attention to are that one is to encourage to set up the distribution system to let all the relevant groups get the payment that they deserve. The other is to enlarge the teacher's group. They should take the responsibility of social education.

\section{Perfect the Supplementary Services to Solve the Worries from the Teachers and Students.}

In a long time, our domestic opening education is in the situation of focusing more on the study rather than service. The course indemnification department in many colleges and universities is set up in a sudden so that its function has not been fully shown. Teachers and students are all disappointed with it. According to current situation, we are in emergency need of three main supplementary services: technical support, relevant training, law indemnification.(1)From the view of technical service, the biggest difference between MOOC and the traditional opening course is the technology source. Only by perfecting the video recording, online curriculum making and relevant technical support can we get the qualified video resource. (2)Since MOOC have been developing, the relative education technology will be updated, so the relevant training has become the powerful support of MOOC. Although many colleges and universities 
have opened diversified modern education training course, but its content and pattern are too old. And it also lack of long term plan.(3)From the view of law protection, the commercial mode and openness of MOOC have make itself in the great need of powerful law protection. Copying other people's opinion during the curriculum construction should be blamed. At the same time, online course also belongs to the digital media product, so it is easier to meet conflicts in the play rights. The law department should be established to protect the intellectual property of teachers and discovers.

\section{Conclusion:}

Application-oriented universities mean universities stress their education feature of application. They chose to develop MOOC to help the whole society member, especially the higher education worker to rebuild the relationship between teach and learn, reestablish the evaluation of education, recreate teaching management pattern from society property, scientific property and manage property of education.

\section{References}

[1] Wen-junWu, Wei-fengLv. MOOC in age of big data [J].Computer education, 2013, 20:9-10. (in Chinese)

[2] Xiu-sheng Qu. The influences and strategies of the domestic college course from MOOC [J].Journal of Changchun College of Education Research, 2014, (1). (in Chinese)

[3] Song-yang Lao, Xiao-ping Jiang, Ming-rui Lao. In post-IT era MOOC have influence on higher education.[J]Journal of Higher Education Research,2013,(9).

[4] Dan Hao. The document analysis of domestic MOOC research [J].China Distance Education,2013,(11). (in Chinese)

[5] Ying Wang, Jing-lei Zhang, Zhang Baohui. Special program analysis and inspiration of MOOC [J].China Distance Education,2013,(4):67-75. (in Chinese)

[6] Xiao-hua Zhou. American university MOOC development research [D].Master's thesis of South China University of Technology,2013. (in Chinese)

[7] Hu Zhou i. Present situation research of application-oriented personnel training mode in new universities.[D]Master's thesis of Nanchang University,2011.

[8] Mao-yuan Pan. Theories and practice of application-oriented personnel training [M].Xiamen University Press,2011(3). (in Chinese)

[9] Li-ren Wang, Jian-min Gu. The exploration and problem of the application-oriented personnel training in domestic universities [M].Zhejiang University Press 2008(7). 